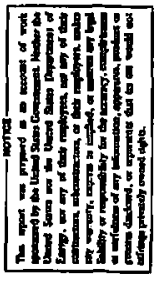

SLAC-PUB-2171

August 1978

(T)

gauge THEORIES OF THE tEAR INTERACTLOAS*

H. Quitn

Stanford Linear Accelerator Cancer

Scanford Univerakcy. Stanford, California 94305

Lecerure I

Aousdoys ic scems almost unnecessary to moctvace a discugston of gaugo theorles of the wak Intoractions-they are fagt becoming the aceepted dogag, Furcherwore one particular varsion, the Heirberg-Salan varadon, 1 or (more opecifically in the context of charm) the Weinberg8alam-Olashow-Ilfopoulos-Matant ${ }^{2}$ vergion aeems to be able to explats woat of the relevant deta, though some areas aro at:11 uncleax, especlally the question of paricy violotion in atonic physics. Hy lectures w111 focus on this model. I vill try to leave you with some feeling for how It Is put togethar, whtch along the way vil allos combent on some poastble variations, many of which exdst in the literature.

In opite of my fitst diaclatmer let wo begin with a é aton of the Improvement afforded by gauge theortes over che1r predeceg80r. the four ferst thsory of veak interactiona. Thet theory vas euceenaful in describing the phenomenology of low energy veak inceraction (euch as angular and energy distributions of product particles in A-decay) but was not completely satisfactory for two (clokely related) reagons: At ouffictently high energy (n 300 Gov) the predictions violate unitaricy, and any attampt to perform highar order calculations is plagued by infinities which cannot be removed by renocmalization. We needed a theory wich could remove these tso problems rthouc changing

Sthork suptorted by the Department of Energy.

(Hresented at the Summer Institute on Particle Physics, Weak Inceractiong, Present and Future, stanford, CA.. July 12 - 21, 1978) 
the 100 energy predtctions-gauge cheortas provide outh a theory. In addition, each gauge model ane vrites down takes a host of new and testabla predictions. Weinberg in 1967 wrote dow "a theory oz leptong" as a firat atmplo example of such a theory. This model, extended to incorporate hadranic veak interactions by tacerting the quarke by analogy to the leptone, gives a rearkebly suecesaful phonomenology.

When Helnberg vrote his model he hoped tt sould solve the above centloned problems of renormalizabilicy and untearfty--chat it did inboed do so woo shown somethat later. ${ }^{3}$ Io a four-ferml or curreat-curtent theory we star, wth a weak charge-changing eurrent, epplrically determined to be of tho V-A type, for axnmple for leptons

$$
j_{a}=\overline{u \gamma_{\alpha}} \frac{\left(1-\gamma_{5}\right)}{2} v_{\mu}+\overline{a r}_{a} \frac{\left(1-\gamma_{5}\right)}{2} v_{e}
$$

(I ahall use Bjorken and Drell conventions throughout, and notice that $V-A=1-Y_{5}$ with oy definitions. Also I wil often write particle nameg to stand for the Dirac splnor for that particle.) The walk interaction applitude is then

$$
\frac{46}{\sqrt{2}} \mathrm{~J}_{\alpha} \mathrm{j}^{\mathrm{a}}
$$

(The factor of 4 asy look stange, 1 conpansaces for the fact that I have witten $j_{p}$ wth $\left(1-\gamma_{5}\right) / 2$ rathex than the old-Eashioned $\left(1-r_{5}\right)$. This definition will be conventent to maintafn when we get to gauge theorles stnee $\left(1-Y_{5}\right) / 2$ is the correct projection operator for lefthanded fermions, In fact one usually gees the shorthand $p_{L}$ for $\left(\left(1-\gamma_{5}\right) / 2\right)$ u Iv gauge theory papors.) 
The Interaction (I.2) can be repredented diagramatically, for

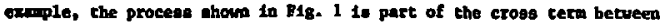
che elactron and wow pleces of the curtenc. The Idea of Introfuctag an Internediace vector boson to try to damp the high energy brouth of thle amplitude predetes LEe gauge theory realieation by tome time. Nalvely one aght hope the diagram of E1g. 2 for whdeh the aplitude is given by

$$
A-s^{2} j_{a} D^{a g} f_{B}^{t}
$$

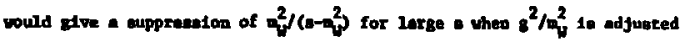
to give tho corrset $10 \mathrm{w}$ energy acreageh. Glearly chlo requires $\mathrm{m}^{2}$ to be large enough that at present everglee the ptopagator is affoctively a conetent, in ordar to malntain the good regults of the current-current theory. That is easily enough achleved, hovever in thit stmple form the Idea does not work for all posalble procenges. In this process $-\bar{\nabla} \nabla_{e}+\mu-\nabla_{\mu}$ it provides the necassaty ouppression, but when looking at other procesaes, for extiple, $\mathrm{e}^{+}+\mathrm{u}^{+} \mathrm{u}^{-}$and oven $\mathrm{e}^{+} \mathrm{e}^{-}+\mathrm{W}^{+} \mathrm{w}^{-} \mathrm{y}$ one finds condn probleas yth untearity. The problem to that the propagator for - angalve vector particle has the form

$$
D_{\alpha \beta}(q)=-1\left(g_{\alpha \beta}-\frac{q q_{\alpha}}{a^{2}}\right) /\left(q^{2}-\alpha^{2}\right)
$$

The term proportional to $B_{a \beta}$ has Indeed the destred behavior in all cased but the $q_{\alpha} q_{\alpha} / m^{2}$ term in some processes can give terms of order $q^{2} / m^{2}$ which cancel out any large $q^{2}$ auppreasion from the denominator.

After gauge theories had been found to be a workable way to c1rcurvent thla problam several people asiad the queation "Are they the only way?" In the following form: Suppose I etart with the vectors and 
quarks coupled a in the procegs (I.J) and allov in addicion ceutral vactor and acelar particlea in the theory with arbitrary maseee and coupling constante. Now I require tree graph unitar1ty. ${ }^{6}$ this in that the partial usve amplitudes genereted by the oun of troe graph dLagrama for a given process should not grow wote rapidly than $s^{2-\text { th }}$ for 2 particle processes. Impoating this condfcion on a auffictent1y Iarge set of atplitudes gives relatlonohips among the magses and coupling conacants (Yukawa couplings and vector-gcalar couplinge as vell an vactor-vector. coupliage). In every case the set of couplinge so decemined we set which one could derive by butlding a gauge theory with the ware particle content !

Heving come as far, lat on ow oplatn how to butld a gauge theory. The recipe ia simple $\mathrm{e}^{5}$

I. Choose a gauge group.

II. Choose fermion reprasentation content.

III. Choose HIgge ncelar reptegentation content.

IV. Arrnge for aponcansoug aymatry brealzing to give a nowvarish1ng vacurm expectation value for oowe scalar or ret of Bealore.

of cource all chls needa wo furcher explenstion to be veaningfuland gom clovernesg in following the ateps to arriva at a poselble theory of the weak and electromagnetic intersctions--there are many theories I could srite folloring steps I to IV whtch would not be viable for this purpose-for erample it 1s trivial to arrange that only one magless vector survives after the spontaneous symetry breakdng but it 18 somewhat more complicated to arrange that that veetor has the correct coupHngs to be a photon. 
Let us etart uth otep I. that do I do then I choose a gauge group. In a gauge theory the vector mesons are slways in the adjoint repreasntation of the group, so chooding a group tells we how wany vectoz mogons I heve, and defines the way chey couple to ona another. In less group theoretlc lenguage "In the adjolnt repregentation" meang there is one vector mesan for each Independent atructure matrix $\lambda^{a}$. In su(2) tho otruekuze matrices are the act of traceless unitary $2 \times 2$ morrices, the Eamilar Pauld d-matrices, of which there are three $((2 \times 2)-1)$ so $30(2)$ aene three vectors. A product of groups auch as $\operatorname{SU}(2) \times U(1)$ had as many vactore as needed tor each factor group aeparately so $\mathrm{SU}(2) \times U(1)$ has fout vectors, $s u(3)$ hes elght $((3 \times 3)-1)$, etc.

In deriving vector couplinge it is compentent to define the matrix

$$
A_{\mu}=A_{\mu}^{a} \lambda^{a}
$$

Stnce every term in the Bamiltonian (or Lagrangian) mugt be scalar (anglet) under the gauge group te em readily construet possible terms frow the objects (I.S) by taking traces, for example

$$
\operatorname{TR}\left(A_{\mu} A_{v} A_{6}\right)= \pm f^{a B \gamma} A_{\mu}^{a} A_{G}^{B}
$$

1. a group singlet shree-vestor terw. The structure function $\mathrm{f}^{\mathrm{aBY}}$ is defined by

$$
\left[\lambda^{a}, a^{A}\right]=1 f^{a B Y} \lambda^{\gamma}
$$

Of coures the Lorents indices in (1.6) must also be contracted in some way to glve it the correct Lorentz Invariance propertles. Hou we cowe to atep II, choosing the representation content of the formions. Let us discuse thit and subsequent steps in the context of su(2) $\times$ u(1) In order to give concrete examples. Choosing repregentation 
content simply means choosing which multiplets of Eerrions we are to intraduce. The Weinberg Su(2) is of ten called weak 1sogpin, a prlort we tray choose fermions as weak 1sospin singlets, doublets, triplets, etc. In doing this one treacs the left- and right-handed components of the fermions completely geparately. The sholec we make $1 \mathrm{~g}$ gufdod by experiment. Let us atart by exaning Welnberg's cholces for the leptong. He chose lefthanded doublets

$$
\left(\begin{array}{c}
u_{e} \\
e
\end{array}\right)_{\mathrm{L}}\left(\begin{array}{c}
u_{\mu} \\
\mu
\end{array}\right)_{\mathrm{L}}
$$

ard stght-handed singlecs $e_{k}, \mu_{R}$ and the otandard Heinberg-Satan model extends this choice to quarkz

$$
\left(\begin{array}{l}
u \\
d_{d}
\end{array}\right)_{2}\left(s_{c}^{c}\right)_{L} \ldots . \cdot u_{R}, d_{R}, s_{R}, c_{R} \ldots .
$$

where

$$
d_{c}=d \cos \theta_{c}+s \sin \theta_{c} \text { and } \theta_{c}=-d \sin \theta_{c}+\theta \cos \theta_{c}
$$

Why these chotcee? Eor the leptons they are clearly the simpleat posAble cholce, which allows us to couple to the SU(2) vectors, to lefthanded fermlons. Using the group singlet quantity

$$
\left(v_{e}^{e}\right)_{L}^{\dagger} Y_{0} \gamma^{u}\left(A_{\mu}^{a} \cdot \sigma^{a}\right)\left(\begin{array}{l}
v_{e}^{e} \\
e
\end{array}\right)_{L}
$$

While the $U$ (1) vector can couple to both Iaft- and right-handed fernions

$$
\left(\nu_{e}\right)_{L}^{+} \gamma_{0} \gamma^{\mu} B_{\mu} \cdot I\left(\begin{array}{l}
\nu_{e} \\
e
\end{array}\right)_{L} \text { and } e_{R}^{\dagger} \gamma_{0} \gamma^{\prime \prime} B_{\mu} e_{R}
$$


A1 I am do1ng here 1a conerueting group atnglek objocts of the forw

$$
\sum_{a, b} F_{a} r^{p}\left(A_{\mu}^{a}, A^{a}\right)_{a b} b_{b}
$$

Glansy if ay fermione are in exiplete the matrices $n_{a b}$ must be the $3 \times 3$ reproventations of StI(2) and wo on.

It is Inediately clear froe (I.10) why Nalnberg did not stop at su(2). If ve urite out thile apreandon we have

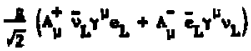

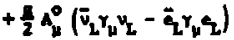

The charge-carrytot vectore $A^{+}$and $A^{-}$hrve boen constructed co couple to the correce veak currenta of (I.4), but the nautral particle 1s not a pod photon candidate, it couplea to the electron with a V-h coupling, and It alos couples to the neutrino. Weinbers added the U(1) factor,

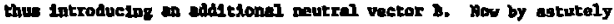
choosing the reIncive otrangthe of the left- and right-banded couplinge of the $\mathrm{a}$ it cen be arranged that there is a inear comblostion of $\mathrm{A}^{\circ}$ and D whlch has pure vector coupling to the electzon and which does not couple to the neutrido-thus this linear combination is a candidate photon. However thoze is than Inevitably another (orthogonal) Iinear coblontion of $A^{\circ}$ and $B$, cull it the $Z$, whth couples wth gome well deffind ant of couplinge, adxture of vector and axtal, to both neutrinos and electrons. It is only a wateer of algebra to find 12 out. I recosend thot you should carty through this exerelee, starting frow (1.10) and (I,11). Defining 8 as the coupling of the sU(2) vectors to the termilon doublet and $8^{*} / 2$ for the B-coupling to the left-handed 
doublet couping one finds the relationahip

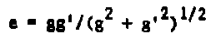

Oae free parameter is left, it is ugualy uriten os

$$
\sin \theta_{w}=g^{1} /\left(g^{2}+g^{2}\right)^{1 / 2}
$$

How to the quarks, or . wn the muon; wht datermines that I should agke the sawe aselgnmente Inr them, ospecially for the right-handed perts, oince slearly I have enough right-handod quarks to put aone or al1 of them in nontrivlad multiplece too. The anpwer 18 phenomenology; the Iollowing pointe are importent:

(1) cobibbo univaraaltey

The relationshtp batwea $u$-decsy and 8-decey lo wose reedily achleved by the cholce (I.9). For examplo if I put the a and $d$ quarixg as najghboring members of a criplet then theit coupling to the $\mathrm{w}^{+}$would have a fector of $\sqrt{2}$ relative to the wuon and electron couplings (olnoly - Glebach Gordon eneffieient which 1s different for different iaotopic opin aagigaments.)

(11) The $u$ and $d$ couplinge are igtt-hooded, at lesst at pregent energles. Thus if ${ }_{k}$ or ${ }_{k}$ axe members of nontrivisl muttiplets of the su(2) they nuat be in differant eultiplete, paired with heaver quaris. As wo wll see later pregently exdoting late from v-ecattering does not altow a doublet righe-banded assigmmente for $u$ and $d$ wth quarizg of megs less than about $5 \mathrm{GoV}$.

(1ii) The repetition of the $\left(u, d_{c}\right)_{L}$ by the $\left(c, s_{C}\right)_{L}$ is a manffesta-

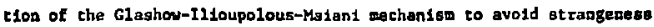
ehanglng neutral eurrents. That wust be ouch an old scory around here 
these daya that 1t scarcely needs to be mentioned. What way not be so wll know 1e that natve generallzations to further flovors auch as $(t, b)_{L}, c_{R}, b_{R}$ wolds all flevor changing neutral currents-the rule $1 a$ that I musc assion all left-handed quarks of the eame charge to the same wutiplet (posttion ond typa) and olodlarly for the r2ght-handed quarkg to avodd the generation of flavor changing neutral currencs. ${ }^{6}$ so far ve have Litrle experfuencal evidence on the subject, buc the theorecical Iterature ta havily biased to chis direction.

I a trying to make clear the ad hoc nature of the construction. Wthln the bealc reclpe many varlations are posible, even once I comptote atap I thate are many chotseg at step II, etc. The beauty of the ger If that each wholce gives wany predictions. Tho hiotory of the fleld is a tribute to the experimentaligts, who secm to be able to elfminote wodele anose as fagt as the theoriats can cook thew up (following the refpo). Of course, the asce that io known the harder the gane of cookins become-chere are more and more conetratnts that a model must atifify before it il even yorth diacussing. Wore renarkable yet, che

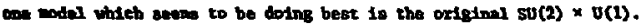

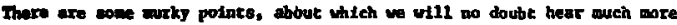
In the next reak or so. In particular, in atowie physics parity violatwoos and $\bar{v}_{\mu}$ e ecattoring experimente differ, but there is posolble conEltet wth the nodele. However the model is doing well enough that I dul continue to treat it here as the prime candidate cheory. Let we then proceed to steps III and IV of the recipe which introduce the H1ges sector. Why put is Higgs at all? The question can be aked at varinus levels of aophiotication. Let we begin by proceeding 
natvely, which in this concext raally meane perturbatively. Fow the unitarity argmencs given garlder, in particular one finde the sealars are weeded if the $H$ and $Z$ are aesumed to be massive. From a thoortats viewpoint it is a question of rriting a Lagrenglan with a fivea nonAbellan gauge 1nvarianso, which a priort means masslese vectora, and io addicion a chirsi invariance whlch weans aleo maselese fermitone. How we want a way to introduce vector and fermion massee vithout destroying the renormalizability of thac theory. The onty way to do this which glve perturbatively calculable predicticng is to introduce lamintary acelars which couple gauge-1avartancly to the vectore and vid Yulusa couplings to the fermilong. The "Biggs" triek Involves arcanging the wres $\left(\phi^{2}\right)$ and self-1nteraction $\left(\phi^{4}\right)$ parameters of these acalars so that a novaniahing vacunm expectation appeare for some wealar-this is celled spontaneous syumetry breaking, despite the fuct that it is obout as apoateneove as the appesiance of a horga in a corral. (I firat hutld the corral and herd the horana if I viah to have the efiect occur.)

What doas a ponvanishing vacula expectation value for a fleld menat It meane that quanta of the theory, to ubich I can galve a particle interpretation, are simply quancum fluctuations about sezo of the variable

$$
D=-\nabla
$$

where $v=\langle\phi\rangle$ is the vacum expectation value, as opposed to eluctuarione of Itrelf abour zero. Hence it is conventent to change vartables and rewrite the Lagranglan in tarms of $p$. I can represent this procesas dtagramatically by witting 


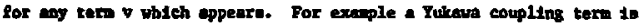
ohow is rig. 3. Clearly

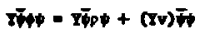

and wa we that o quack ana term (TV) has appenred. S1milar1y the tern:

$$
8^{2} s^{2} a^{a}
$$

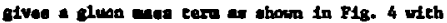

$$
n^{2}-s^{2} \nabla^{2}
$$

Bow do I achlowe nomvantshtng vacuun expectetion value? Everyore by

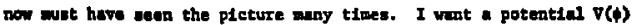

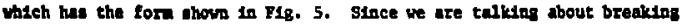
a contimous byotey, the phase eymetry of $\phi+e^{10} \phi$, tha plature is thrae-dinengtoral--the raxican hat potential. In a acalsr Ifeld theory

$$
\nabla(\phi)=\mu^{2} \phi^{2}+\lambda \phi^{4}
$$

ware $w$ and $\lambda$ are the paranetere appearing in the Lagrangion. Obriously, Degotive values of $\mu^{2}$ give the deatxed ohape. Sotice chat although $\mu^{2}$

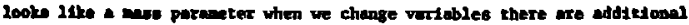
ceatar eaes terco proportionel to $\lambda v^{2}$, so that there $10 \mathrm{mo}$ problem of negative (nat) ${ }^{2}$ tor phyated sealex particles.

Bafore I get too far from this picture let me comment on mother obvioun fanturs of It. The choice of the direction of vacunim expectaeton valu in the $\left(\phi_{\mathrm{Be}}, \phi_{\mathrm{I}}\right.$ ) opece in arbitraxy, no phage te prefarrad. This and that for any value I choose there is one mode of osell1atton about that value whth has zero frequency, It is along the ofinimu of the potential. This to the Goldstone phenomenon whtch happens whenever 


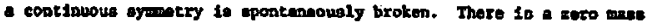
particlo eqsoctated with wuch a 2 . 0 frequency wode. The trick of the

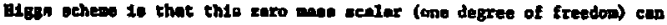
be eatea up by the seto man vector (two degrees of freedue) to give a anotva vactor (three $-2+1$ dejraen of fraedom). slnce thure do noe

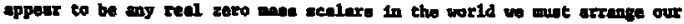
A19ge aetox in such a way that evary such coldatone boson corraponds

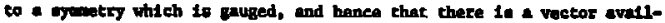

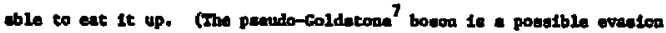
of this tule, it any bopen thet there 10 a oywetry of Higge tagranglan which 1s not a opoutry of the full Legranglen. If auch a eymetry is epoptancouly broked it will appear in a lovest order celculation of the type funt digcuened that there to a maslene scoler, but haptis highar order effects from the vector waono will gave this particlo a mact. $j^{8}$

Atter all these prelininaries we are ready to perform oteps III and IV. In su(2) $\times \mathrm{U}(1)$ with the ferwion easgmente whleh we beve juat made we need at least one Blgge doublot. Yulure couplinge ore of the fort

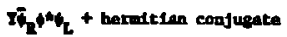

The right-handed alectron is in an su(2) a1nglet and the laft-bandad electron is In a doublet. The only genlar mepresentetion shoich with allow ouch a coupling it a doublet. Here is yet another reason for

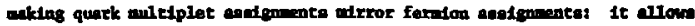
one to be economical in the Higgs eactor. Suppose I ware to ehoose to put the right-handed up quark in a high 1roppin multiplet. Firet I would have to introduce pecullar now quarks (chargeg other than $-1 / 3$ or 
2/3) to t111 up the aultiplet, and then I wauld oeed addit1onal H1gge conteat to contrive to give the up quarik and the rest of Ite new cousing

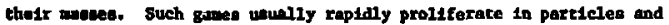
10 uelenase.

UIth atandard SU(2) $\times \quad \sigma(1)$ asalgnments I can get by with only IIgge doublet: of the forth

$$
-\left(\begin{array}{l}
\phi^{0} \\
\phi
\end{array}\right)
$$

The charge conjugate doublet

$$
\dot{\phi}=\left(\begin{array}{c}
\phi^{+} \\
+^{+}
\end{array}\right)
$$

1. then alwo present. Ep-type quarks get sase fron Yukms terws of the trpe $\bar{u}_{k}+\left(\begin{array}{l}u \\ d\end{array}\right)_{L}$, and down quarte (IIke electrons) need $\bar{d}_{R}+\left(\begin{array}{l}u \\ d\end{array}\right)_{L}$ souplingo. I beve defined the charges in relationahtp to ay provlowsily deLind photer. Itret photes en only stay nassiegs if only the neutral part of $\$$ has a nonvantehlng vacum expectation value. Bemenher the photon was defined siuply as that linear combination of tho $A^{0}$ and $B$ partele which coupled to the electron with a vector coupling and decoupled frow the peutrino.) The $\nabla(1)$ factor to o byperebarge, in toneral this photon couples to electric charge, dafinad as

$$
Q=T_{3}+8 / 2
$$

and we sen arrange the hyperchurge to get the otonderd quark charges, and the chargas defined above for the scalars.

In wy next lecture I wil write out the Lagranglan to shor how all this works, A few more coments can be made without doing so. I have satd we naed at least one complex Higs doublat, for mogt of the rest of 
w lectures I will talk as $1 f$ therg to only one doublet. The exiateace of additional ecalas doublete does not change the phenomenolngy of the lepton quarks and vector mesons very much, though it hecomes important when ftner poincs auch as CP invariance and of caurse scalar particle

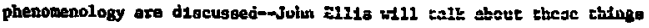
1ater in the achool. However the motter of whecher there are in addtIon to the doublet other acalar repregentatlons st:ch as triplets does Indeed affect the phencmenology. Wa will shortly see thac dsouning only H19gs doubleta laads to the mass selationthip

$$
\pi_{x} / m_{2}=\cos \theta_{n}
$$

Addiog a Higgs eriplet with a nowvanighing vacurim expectation valce for It: woutral nerber would chang thls relationobfp, alloulng the 2-mase to he lnereased arbitrac1ly, thup veakening the effective strength of the 100 energy (B ex $\frac{2}{2}$ ) neutral ctrrent effects. Using only doublate the $50(2) \times U(1)$ theory predlcts the curve show in F18. 6 for the rat1o of aeutral current to charge current totel erose sectlon for neutrinos and for antineutrinos. Each point on the curve corresponda to a value for $\sin ^{2}$ oy. As the E1gure shous the experiwestal values axe eonetatene Ath this prodietion for a value

$$
\sin ^{2} \theta_{0}+.2-.3
$$

ao apparently wo do aot need to add any triplet Higes. To do ao vould relax the prediction of the model, Instead of the line we could adjust paramoters to yleld any potor in the cone enclosed by the two dotted 1foeg and the Neinberg-Salem prediction.

AIl this is just a brief ineraduction to the rules of che game of model but1ding. Tha tratn points I want to etress in this lecture are 
that the Idea of a gauge theory of the veak interactions 1s very general and allows many epectifc realizations, of with the etandard SU(2) $\times U(1)$ model 1a ouly ane. The ecructure 1s very rich and flexible, but flextbillty 1o vougliy abtalned at the price of introducing wore and more particles. The beauty of Neinberg-Salam-GIH 1 s that so faz it has fit a lot of deta uhlle being quite economical in particle content. If it survives the parity violation teat 10 (which rasne if either the Nowolbirak experiment and the theorecieal atomic physics calculations, or the Oxford and both the Veshington expordmente, are wroug) ve ofll have a renarkable candidate weak interaction choory. If not chen the theorinte wuat so back to work to produce a wodel whtch cen fit the stac resulta for par1ty volation in polarized electron acattering and the econte phyelcs-no doubt several people arc already working bu such -ndela.

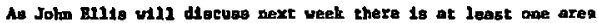
where the prodictiong of these theorfes ramin virtually untested-the Higgs sactor. So far no we has seen any direct effect of these particles. They have been Introduced in a sonewhet arbitrary fashton to allow ua to urite a remorralizable theory wth vector and fermion mases; one with which ve can perform perturbativo ealeulations. There 18 a school of thought among theoriste which oags that elementary scatars are ugly, perhepe the same effects ean occur dymanically frow formation of boundstates in the scalar chumels. The problem is that ve canant do wuch mord than enggest tiee posstbility, tle 1dea takes un begond the realm of percurbation theory and hence, for the wost part, beyond the range of our ability to calculate. 
One could go even further and add that ve heve no direct eoldence for the vactor sector. (Again John Ellis will discuse the phenowenology of this sector later th1s week.) $\mathrm{Bj}^{11}$ for ana, has tried to introduce a note of caution Inte the ganaral bandragon accaptance of gauge theorica as dogma by discussing hos truch of the phenomenology can be obtalned by making weaker assumptiong-auch as sywetry propertieg without neceggerfly assuming gauge realizationg of them-and he concludea that nothisg in the pregent data compele us to accept the gauge theory plctura. Howerez neither does anything preclude us from dolng so, 00 for the next veck we vill continue to 1 gonore all alternatives and diccugs, ae the title of chts lecture geries states, only the gauge alcetuasives.

\section{Lecture II}

Yeaterday I managed to be very general and arolded witing any decailed algebre. Today'a leceure wll be mueh wore detalled, as ve Investigate all those ganeralities in the context of the HelubergSalam $\mathrm{sU}(2) \times \mathrm{U}(1)$ and see how one arrivas at apecific experimantenl predictions, a few of which 1 have already mentioned.

There are turo typen of execcisa which ve must purave. The firot 18, orce $I$ have told all thare to to tell about gauge group and paxticle conceat, to read off from that whatever we can about the phyatcal couplings ard wass relactonshtps. The second 19, given the couplings, to compute cross sectlons.

I w11 write dosm the full Velabig-Salam theory and them ve will Investigate it piece by plece to see the phenonena discussed yeaterday at work. 
Let ae defing

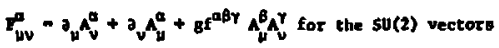

201

$$
a_{u v}=\partial_{\mu} B_{v}+\partial_{v} B_{u} \text { for the } v(1) \text { vector. }
$$

Purther 1et

$$
\psi_{L}^{1}-\left(\begin{array}{c}
a_{L}^{1} \\
b_{L}^{1}
\end{array}\right)
$$

were 1 runs over both leptons and querks. Than

$$
\begin{aligned}
& \varphi=-\frac{1}{4} P_{v v}^{a} v^{a \mu v}-\frac{1}{4} G_{w v} c^{w v} \\
& +\sum_{k}\left|\left(\partial_{\mu}-\sin _{\mu}^{a} \sigma^{a}+ \pm \frac{8^{\prime}}{2} B_{u}\right) \phi_{k}\right|^{2}
\end{aligned}
$$

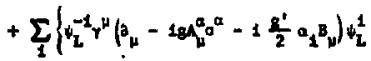

$$
\begin{aligned}
& \left.+-_{R}^{-1} \gamma_{\mu}\left(a_{\nu}-1 \frac{B^{\prime}}{2} B_{1} B_{\mu}\right) a_{R}^{1}+b_{R}^{1} \gamma_{\mu}\left(a_{\mu}-1 \frac{g^{\prime}}{2} \delta_{1} B_{\nu}\right) b_{R}^{1}\right)
\end{aligned}
$$

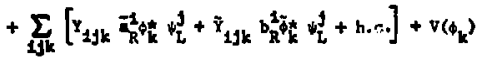

How ve aholl proceed through wet of triviel exercises in algebra with the Lagrugian, assunteg the Elgge potentsal is such that the vacum expectation value

$$
\left\langle\sum_{k}\right\rangle_{\text {vac }}=\left(\begin{array}{l}
v \\
0
\end{array}\right)
$$

For olmplicity we will carry out these exercisce as if there is only ope cane in this sun, that is as if there to only one doublat. If theze are many doublete ve can aluply define that (normalized) linear comblnation which gete nowvanlshing vecum expectation value to be $\phi_{1}$ and then the 
following diacusaton 16 valid for $k=1$.

Exerctee I. What are the vector wase rezus? We have in tho Lagrangian

$$
\begin{aligned}
& \left(\left.\left(\alpha+\cdot \vec{a}+\frac{g^{\prime}}{2} \mathrm{BI}\right)\left(\begin{array}{l}
\phi_{0} \\
\phi^{-}
\end{array}\right)_{\text {vac }}\right|^{2}\right. \\
& =\left|\left(\frac{8}{2}\left[\begin{array}{cc}
4 & \sqrt{2} A^{+} \\
\sqrt{2} & -A_{0}
\end{array}\right]+\frac{8^{\prime}}{2}\left[\begin{array}{ll}
B & 0 \\
0 & 8
\end{array}\right)\right)\left(\begin{array}{l}
v \\
0
\end{array}\right)\right|^{2} \\
& -\mid\left(\left.\begin{array}{l}
\frac{1}{2}\left(g A_{0}+g^{\prime} \theta\right) v \\
\frac{g}{\sqrt{2}} A^{-} v
\end{array}\right|^{2}=\frac{1}{2} g^{2} v^{2} A^{+} A^{-}+\frac{1}{4}\left(g^{2}+g^{2}\right) v^{2}\left[\frac{B A_{0}+B^{\prime} B}{\left(g^{2}+g^{2}\right)^{3 t}}\right]^{2}\right.
\end{aligned}
$$

Thuo, Identifying the magatve aeutral state ad $\mathrm{Z}$, we have

$$
z=\frac{g A_{0}+B^{\prime} B}{\left(g^{2}+g^{2}\right)^{h}}=\operatorname{ros} \theta_{H} A_{0}+\sin \theta_{p} B
$$

we cur read off the magea from (II.6)

$$
z_{z}=\frac{1}{\sqrt{2}}\left(s^{2}+s^{2}\right)^{\frac{1}{2}} v \quad \mathrm{w}_{\mathrm{v}}=\frac{2}{\sqrt{2}} \mathrm{gv}
$$

This gives the advertized rat10 $\mathrm{m}_{\mathrm{N}} / \mathrm{m}_{2}-\cos \theta_{\mathrm{w}}$ and the orthogonal combjation to the $z$, the photon.

$$
A=-\operatorname{ain} \theta_{w} A_{0}+\cos \theta_{w}^{3}
$$

clearly bas zero mass, by congtruction.

Eere we have defined a photon as the linear combination of $A_{0}$ and B whlch gets no mass. How for Exerclse II ve cen go back and check how to thoose $\alpha_{1}, \beta_{1}$ and $\delta_{1}$ oo that this particle has pure vector couplingo 
$-19-$

W th the right coefficients, that io

-1 for electron, mon, tau, etc.

$q$ - 2/3 for u quark, e quark, etc.

(II. 10)

$-1 / 3$ for d quark, o nuark, etc.

To do thin scare by afopiy rewriting the relevant terms in taros of $\mathscr{P}$

and waiting

$$
A_{0}=2 \cos \theta_{w}-A \sin \theta_{w}, \quad B=2 \sin \theta+1 \cos \theta
$$

Ne flat the fermion couplings to neutral vectors are

$$
\begin{aligned}
& =\bar{a}_{1} \gamma^{\mu}\left\{\left(\frac{B}{2} A_{p \mu}+\frac{g^{\prime}}{2} a_{1} B_{\mu}\right)\left(\frac{1-Y_{5}}{2}\right)+\frac{g^{\prime} B_{1}}{2} B_{\mu}\left(\frac{1+\gamma_{5}}{2}\right)\right\} a_{1}
\end{aligned}
$$

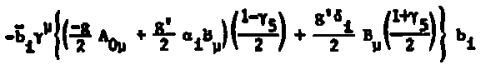

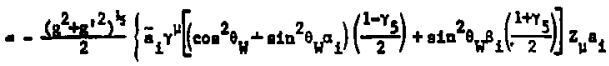

$$
\begin{aligned}
& +E_{1} \gamma^{\mu}\left(\operatorname{asn} \theta_{H} \cos \theta_{W}\right)\left[\left(-1+a_{1}\right)\left(\frac{1-\gamma_{5}}{2}\right)+s_{1}\left(\frac{1+\gamma_{5}}{2}\right)\right] A_{\mu} a_{1} \\
& +\bar{b}_{1} \gamma^{\mu}\left[\left(-\cos ^{2} \theta_{\psi}+\sin ^{2} \theta_{\psi^{2}}\right)\left(\frac{1-Y_{5}}{2}\right)+\sin ^{2} \theta_{\psi} \theta_{1}\left(\frac{1+\gamma_{5}}{2}\right)\right] z_{\mu} b_{1} \\
& \left.+\bar{b}_{1} \gamma^{\mu}\left(\sin \theta_{W} \cos \theta_{W}\right)\left[\left(1+a_{t}\right)\left(\frac{1-\gamma_{5}}{2}\right)+\delta_{1}\left(\frac{1+\gamma_{5}}{2}\right)\right] A_{p} b_{1}\right)
\end{aligned}
$$

The requirement of absence of "s coupling e for the photon immediately Ares

$$
a_{1}=-1+a_{1} \text { and } \delta_{1}=1+a_{1}
$$

The charges of $a_{1}$ and $b_{1}$ are then given by

$$
\begin{aligned}
& e q_{a}=\frac{8 g^{\prime}}{\left(8^{2}+g^{\prime 2}\right)^{\frac{1}{5}}}\left(\frac{1-a_{t}}{2}\right) \\
& e q_{b}=\frac{88^{\prime}}{\left(\mathrm{g}^{2}+\mathrm{g}^{2}\right)^{\frac{5}{2}}} \frac{-1-\frac{1}{2}}{2}
\end{aligned}
$$$$
\text { - } \frac{88^{\prime}}{\left(8^{2}+8^{\prime}\right)^{\frac{1}{2}}}\left(T_{3}-\frac{a_{1}}{2}\right)
$$ 
were $I_{3}$ is the weak tauspln assignmert of the left-handed fermion. Heace ve can Identif; the coupling of the photon.

$$
e=\frac{88^{+}}{\left(c^{2}+g^{\prime}\right)^{4}}
$$

My parameter $a_{1}$ to the negative of the hypercharge. We arrive at the right charge agagnment for leptons with $a_{1}=1$ givios $q_{a}=0$ and $q_{b}=-1$. (Notice that this gives $\theta_{1}=0$ as at must afince there is no ilght-headed neutrino to form a s type coupling with the B.) For quarka we set $a_{1}=\frac{-1}{3}$ giving $q_{a}-\frac{2}{3}$ and $q_{b}=\frac{-1}{3}$. Furtherwore we have now spectified the 2-coupitags wich wit. a 11ttla further algabra ve can venrtice as

$$
-\left(s^{2}+s^{2}\right)^{\frac{t}{2}}\left\{T_{3}\left(\frac{1-r_{s}}{2}\right)-Q \sin ^{2} \theta_{w}\right\}
$$

Clearly the couplings of the 2 are In general a wixture of $v$ and $A$ although a peculiar accident way happen to remove the $v$ part, for example the nogative leptone $e, H$, etc. would havo axial coupling to the 2 if $\sin ^{2}{ }^{2}=0.25$. (Experimenally we wll find the preferred value of $\sin ^{2}$ is is not very far from this velue.) I could at this polot Di oceed to the cext bet of terms-the Yukawa coupling terms, wai carry out exerctee III, whteh is to f1nd the quaxk and lopton uses matrices. I wlll not do wore than mak, a few commonts on tblo everclae-carry it

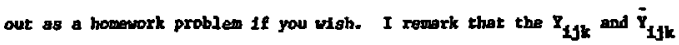
do not require that $10 \mathrm{j}-\mathrm{this}$ has the consequence that the mase efgenotates, the quarks, $u, c \ldots$ and $d, s \ldots$ may be linear comblnations of the $a^{1}$ and $b^{1}$ raspetively. This phenomenon has alresdy be's mentioned, we find Cabibbo combinations

$$
\begin{aligned}
& b_{1}-\cos \theta_{c} d+\sin \theta_{c} s \\
& b_{2}=-\sin \theta_{c} d+\cos \theta_{c} s
\end{aligned}
$$


are the resk eiganstaces. If w introduce furcher quirks with the aam

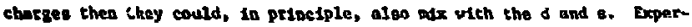

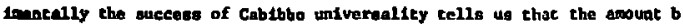

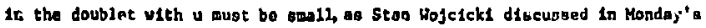
1ecture. The Tukme couplinge mugt then be arranged of that this is 80 . Jugt a fev wore conneate on the rules for puttang cogether theories of the Weinberg-Salas type and then on to real phyoles--that is to eroso enction enlculations. On- of the advertizad virtwed of gertge theorlos conpered to the old for. formi theory 18 reoormatrablitity. In fact the Heinberg-Salam theory as I heve uritten It ta not necessarily jeroralizable-bectves of seonalies, which veane procerges Involving the criendle of F19. 7. One cen take the atecteuds that this don not wuch materer. We hre to 80 to weh h2gh order before there 16 any problew that we 19ht be being unresonably optiolstic to hope that our p:wont theory 10 veltd to that eccuracy. Hevever the dogne gaya we must gat rid of these anonalied that is to wy wa must heve a renocmalizable theory. Wa can axturge to do to by having a number of anch criangle diagrumg vith

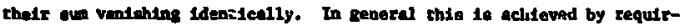
109 the of of the fexmion charges to vanteh. In Heinberg-Salan, with su(3) colot, this happens if one has as many flewors of quor:. doublet an thare ate lepton doublere, 0.8.,

$$
\begin{aligned}
& \left(\begin{array}{l}
v_{c} \\
e
\end{array}\right)\left(\begin{array}{l}
v_{u} \\
y
\end{array}\right)\left(\begin{array}{l}
v_{t} \\
t
\end{array}\right) \\
& \left(\begin{array}{l}
u \\
d_{c}
\end{array}\right)\left(\begin{array}{l}
c \\
g_{c}
\end{array}\right)\left(\begin{array}{l}
b \\
b
\end{array}\right)
\end{aligned}
$$


For each palr of toublete $\mathrm{Iq}_{\mathrm{q}}-(0+-1)$ for leptons $+\mathrm{n}_{\mathrm{c}} \times\left(\frac{2}{3}+-\frac{1}{3}\right)$ there $n_{c}$ Is the nuber of colors of each quark Elavor. For color $5 U(3), n_{c}=3$ and $2 q 0$ uitb this arrangement.

As I acrosecd pescerday thoce is no a prlori reseon for the concinuIng replication of sfillar muleiplets. Assuang such repleation leads to a prediction thit there are no flavor changlng neutral curremte. to the context of this theiry the tadees of the various formione are achleved quite axbitrarily by adjusctog Xukmwa couplinga.

Wo have you written a model which telja'g evarything there ta to know abouc the weak interactions of leptons and of quarks. For leptona the rest to coaplecely acraightforward, we can aloply salculate any process we choose. For hadron phyotrs to r.eed sotwathing more to relote ch1a wedel to expertment-r.y ntod to knoy hou thd quarke are put sogether to make hadrons. That ve do not jeelly know, so ve t.re left, somethot up In the ait by our beautiful theory of the weak inceractiona. However thare is a great deal we can do, In the framowork of the quark-paton model. We defino a set of functions called the atructure functiona chich descrits at leagt part of what we aced co know wey are a buscrlptlon, at lesst in the high ontergy 11mit, of hadron composstion in cerms of quske. He ean then calculate cross neccions for a number of prochoses In terms of these ame functions, and huce tert the thaory by the con-latercy betwoed the varloug rateg-testing whether all experimenta can be fit with the same gat of ot ructure functions.

wet us therefore discuss the familiar exnaple of doap t-delastic gcatco 1ns. For sufflclently high encrgy and momentur transfer we can neglect lepton and quark mases, though clearly if we coms to a new 
quark threshold that rule wil be in abeyance for a while. Th1s means we only have to do very few celculations. alnce tbe Ioteractions $\gamma_{\mu}$ and $\gamma_{u} \gamma_{5}$ each preserve helictity up to corrections of oxder of E. The calculations are simpla enough. I will not go through them here; I vill gimply state the reoulcs for deep tedelegtic gcactertag. I deflne the usual set of variableg for the procesa shom in F1g. 6 .

$$
v=q \cdot p \quad x=\frac{-q^{2}}{2 w} \quad y=p \cdot q / p \cdot k
$$

In teras of the quark-parton model the cross cectlons for varioue deep-inelostic procenaed can be obtafned by adeuming tacoberent ventcorIns off the Individual quark constituente of che target and defining atructure fuactione $f_{q}(x)$ whlch, in the high easey lindt, repreent the probability of fluding a quaxk of type q carrytag a fraction $x$ of the proton's momentum in a fram in wich the proton is woving with very large namencus. This partor ptcture interpretartion of the atructure function in of course trame dependent, but the cross sections whtch ve vite dow are functions of the invartante and hance are not. In a wore generel pteture one finds that the atructure funetions could in fact be fuactions of $q^{2}$ as vell as $x$, the fact tbat to a tirat approximation thay should be $q^{2}$ independent wa firat suggested by by and hence 10 known as Bjorken eealing. 12 In the context of a speetele wodel of the strong Inteructions, namely QCD, one can obtain more detalled predictions sbout these fumctiong and their $q^{2}$ dependence ${ }^{13}$-these predictions vilu be discussed tomorros by John BLlis. For the mowent however let us take the watue paxton model patnt of vieu and treat thase as functions of $x$ alone. Neglecting lepton and yuark masses ode obtains a very stmple set 
of prodictione, namely ocatertag left-handed fecmion on left-handed torwion or right on right gives

$$
\frac{d p}{d x d y}=x f(x)
$$

acatcering left-handed on right-tranded atvea

$$
\frac{d g}{d x d y}=x(x)(1-y)^{2}
$$

Let us look at this for $v(v)$ mueleon $+\mu^{-}\left(\mu^{+}\right)$anything. The charged valk cutront aees only left-handed quarke sad thus onty rethe-handed ent Lquarke, Bo the above rule gives the faniliar predictiong

$$
\begin{aligned}
& \frac{d g^{y}}{d x d y}=\frac{G^{2} q E}{2 x} \sum_{q}\left[f_{q}(x)+f_{q}(x)(1-y)^{2}\right] \\
& \frac{d g^{v}}{d x d y}=\frac{G^{2} y E}{q} 2 x \sum_{q}\left[f_{q}(x)(1-y)^{2}+f_{q}(x)\right]
\end{aligned}
$$

utth

$$
c^{2}=\frac{1}{6}\left(\frac{s^{2}}{2 m^{2}}\right)^{2}-\frac{1}{8 v^{2}}
$$

In Helaberg-Sa2am.

The an: ealeviations cen be wade for tbe deep Inelegtle neutral current neutrino ecattering. To do so it 10 carventent to grite the $Z$ coup11nge as

$$
-\left(8^{2}+8^{2}\right)^{\frac{1}{2}}\left\{\frac{\varepsilon_{L}^{2}\left(1-\gamma_{S}\right)}{2}+\frac{\varepsilon_{R}^{1}\left(1+Y_{5}\right)}{2}\right\}
$$

For sv(?) $\times 0(1)$ theortes we find

$$
\begin{aligned}
& \varepsilon_{L}^{1}=r_{3 L}^{1}-q^{1} \sin ^{2} \theta_{N} \\
& \varepsilon_{R}^{1}=r_{3 R}^{1}-q^{1} \sin ^{2} \theta_{N}
\end{aligned}
$$


In the atendard varalon we had $x_{J_{R}}^{1}-0$ for all fermion types. We notice that theoe formulae apply elther for quarks a antiquarts, and Imply the zelationghips

$$
\varepsilon_{i}^{q}=-\varepsilon_{R}^{\bar{q}} ; \quad \varepsilon_{R}^{4}=-e_{L}^{\overline{4}}
$$

The strcagth of the neutrol eurrent processes ean be eosperod to those of charped curxente. For charged currente the amplitude to proportional to $8^{2} / 2 n^{2}-1 / v^{2}$ wherese for neutral currente the comparable factor 18 $\left(g^{2}+g^{\prime 2}\right) e^{a} c^{b} / s_{q}^{2}-2 c^{a b} / v^{2}$. Thas far exmomile ve obtain tor neutcino deep Inelaatic scatering, ung (II.24),

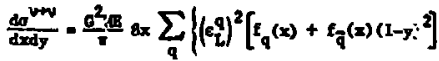

$$
\begin{aligned}
& \left.+\left(e_{R}^{q}\right)^{2}\left[E_{q}(x)(1-y)^{2}+E_{-q}(x)\right]\right\}
\end{aligned}
$$

and stmitary

$$
\begin{aligned}
\frac{d \sigma^{v w}}{d x d y}= & \frac{G^{2} q E}{\pi} 8 x \sum_{q}\left\{\left(c_{L}^{q}\right)^{2}\left[f_{q}(x)(1-y)^{2}+f_{\bar{q}}(x)\right]\right. \\
& \left.+\left(\frac{q}{q}\right)^{2}\left[E_{q}(x)+f_{q}(x)(1-y)^{2}\right]\right\}
\end{aligned}
$$

An obvious note, if the target coptains neutrone and protons then

$$
f_{q}^{\operatorname{target}}(x)=B_{p} q_{q}^{P}(x)+h_{q}^{N}(x)
$$

there $\mathrm{H}_{\mathrm{P}}\left(\mathrm{M}_{\mathrm{H}}\right)$ is the nuaber of protone (neutcons) in the target. Isogpta Invarlance tella us that

$$
\begin{aligned}
& f_{u}^{P}(x)=f_{d}^{H}(x) \\
& f_{d}^{P}(x)=f_{u}^{d}(x)
\end{aligned}
$$




$$
f_{a}^{P}(x)=E_{a}^{n}(x)
$$

and ofodiarly for antiquarks.)

I can treat photon exchange In this ang formalien, the photon coup11ngs can be sriteen in analogy to the z-couplings es

$$
e A_{L}^{1} \frac{\left(1-\tau_{5}\right)}{2}+e A_{R}^{1} \frac{\left(1+r_{5}\right)}{2}
$$

Whero obviously

$$
B_{L}^{1}=B_{R}^{1}=q^{1}
$$

The etreagth factor $\mathrm{B}^{2} / 2 \mathrm{~m}_{u}^{2}$ is replaced by $\mathrm{a}^{2} / \mathrm{q}^{2}$.

For deep inclastic elactron scatcering I can trost the loft- and right-hended parta of the electron tncoherent1y, but $I$ wist remeriber that photon and $z$ exchanges add coherently. Thu $I$ have

$$
\frac{d g}{d x d y}=\frac{d^{2}}{d x d y}+\frac{d x^{2}}{d x d y}
$$

and

$$
\begin{aligned}
& \frac{d \sigma^{2}}{d x d y}=\frac{e^{4}, Q}{4 \pi} \times \sum_{1}\left\{\left[\frac{-q^{2}}{q^{2}}+\frac{c_{L}^{2} q_{L}^{q_{1}}}{\sin ^{2} \theta_{w} \cos ^{2} \theta_{w}\left(q^{2}-m_{2}^{2}\right)}\right]^{2}\left[t_{q_{1}}(x)+q_{\bar{q}_{1}}(x)(1-y)^{2}\right]\right. \\
& \left.+\left[\frac{-q^{1}}{q^{2}}+\frac{\varepsilon_{L}^{e} \frac{q_{q}}{q_{1}}}{\sin ^{2} \theta_{w} \cos ^{2} \theta_{w}\left(q^{2}-\alpha_{L}^{2}\right)}\right]^{2}\left[f_{q_{1}}(x)(1-y)^{2}+f_{q_{1}}(x)\right]\right\}
\end{aligned}
$$

For do $\mathrm{d}^{\mathrm{R}}$ dxdy one stoply sakes the replacements

$$
c_{L}^{e}+c_{R}^{e} ; \quad c_{1}^{q_{1}}+c_{1}^{q_{1}}
$$

In (II. 32). 
Lecture III

Hote tor the reader-this lecture follosed afcer Lecture I by John Ell1s.

I vant to etert this lecture with some comenta on what we have diocusaed 00 tar. In ay firat lecture I cold you hos to bulld a gauge theory wodel. I temind you that It ts an extremely ad hoc procese, good and had codels are distingulghed by experimental teats, not by theoretical reacoolng. Even when a model can be coastructed to fit ell progent dote it makes no defintte prediction about hou any heavier quarke there wighe he, and thore is aimilexly much arbitrariness the piediectons about the ecelar sector. These thinge will be diecused furthor by John Bllig in nubsequent 10ctures, and by Mary Kay Gaillard in the topical conference.

In the recond lecture I told you hor to celculate: Given a wodel, one can read off $\boldsymbol{t}$ and $z$ magee and couplinge and from them proceed direcely to predictions for deep loelastic ecacteriof procesc js, These calculatione are valld in the natve form only uheo it is resconoble to mogleet both the lepton and the quark masses. Near a thrabold, for exple, whets charw production beging to enter in the allowed final trates, the wodel is not capable of giving clear predictions. Thero exist - mubar of alfghtly different auggeations for inciluding quark mass correctione In the nenx threshold reglon. They all Intorpolate amoothly becween the ocaling prediction below threshold and the nes scaling prodiction afficienty tar above. They differ someshat in hos rapidiy the ow value 18 achteved-In other words in hoy far above threshold is suffeteacty far. I vill not go 1nto thia discussion liere. The quantity $y$ plottad as a function of energy for $\bar{v}$ seatcerting has beck used in tho 
Iterature as a particularly sensitfve tegt for the appoarence of 8 threahold corregponding to a right-huoded coupling of a $u$ or d quark to a heavier quack. The reason for t.we cholce in obvious enough, With only left-handed couplinge the velence quark cootribution to antineutrino ecattering is proportional to (1-y) ${ }^{2}$, so a tight-handed coupling, gtving a term proportional to 1 sould glve a marked increasn in $\langle y\rangle$. Bowever the ocaling corrections discusged yegterday by Joho Ells aloo tead to Increase <ys with incressing enargy. The reason for th1e to that the contribution of anc1quarke in the torget 1ncrosese, due to the glue $\rightarrow$ quark-antiquark terms which John discuseed, glving also on inereasing cont-lbution of $y$ independent cross section. I think it to now generally agreed that these corrections ace euffictent to account fot the obcervad vaxtation of sys with enersy, thuo axcluding right-handed coupling of the u or d quarks to any quark ofth ness 1 ees than obout $S$ Gev.

For the thaoriote in the audience I want to sdd one warning (It If obvilous to the experimentera)-every experfment wakes certaln cuts in the data for purely experimentel reasong. In compariog experiment with theory one must know about these cuts and take them inco account. We theoriste have a bad hablt of trying to extrect nubbera feje the expertments to compare direetly with the simpleat theoretical caleniations. What ahould be done is the other way around, one extracte number from the theory (1f necessary via Honte Cario calculationg) to comere directly wth what has actually been measured.

Let we now go on to discuse further predictions uhich ean be obtalned from a gauge theory rodel, as before continuing to use fieinbergSalam $\mathrm{SU}(2) \times \mathrm{U}(1)$ as the sample model. Obviausly pucely leptoafe 


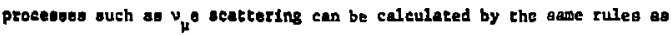
deep Inelastic, simply roplacing ntructure functions by delen-function at $x=1$. For $\bar{v}_{e}$ e or $\bar{v}_{u}{ }_{\mu}$ acatteriag ose wust remember that there 10 a dixect chamnel W-axchange diagram to ipclude an wall as the t-channel zexchange. The predictions are usually given in terms of $B_{V}$ and $B_{A}$, in terwa of the previoualy defined 2-couplinge

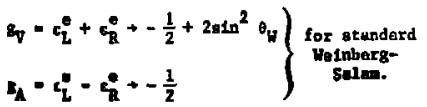

The apporimentel afturtiod to ohoun in P1g. 9. There is one further ranult frow Gargamelie which is in conflict with the other expecimente, and with the Heinberg-salan prediction, however, it appears that the andysis of the second hall of the data will algalf 1eantly change the renult, so I do not includo it here.

The next area where the theory con be tested is in elastic up acattering arpari ents. One wev unitnow function encera-the arial form faccor of the proton. Howtver, one can make cessorable model for this, In parallel to the bahsulor of the vector form factor. In the context of wuch a wdel the Weinberg-Salam prediction ig In good agreemont with the coucureneace, ${ }^{15}$ for $\sin ^{2}$ on in the ragge -2 to .3 .

Becently wike Barrote and Larry Abbock ${ }^{16}$ have made a very nice assenatic atudy of predictions of neutral current process, including cead-incluatve procesese. They find this gaves them a good tool for distingulshing between 8auge theory modelo. Mike will be talking about this in the copical conference, so I will got discuss it further here. 
Now we come to the toptc of the firot. oorating of the topicel sooforence, parfty vinlations. Let we stert wth the asy cases firct. I refer you to a paper by Bob Cahn and Fred G11man'tor the decasls of the eateulotions. Jatng the deap inelastic gcattering formules given in lecture II one orrives at the following predictiong

$$
A(x, y)=\left(\frac{\dot{d}}{d x}-\frac{d 0^{R}}{d x d y}\right) /\left(\frac{d u^{L}}{d x d y}+\frac{d g^{R}}{d x d y}\right)
$$

Por deucarfum, keeping only valence quark contribuctone

$$
\begin{aligned}
& A_{\text {ed }}-\frac{-G^{2}}{2 \sqrt{2} \text { xa }} \cdot \frac{9}{10} \cdot\left[\left(1+2 T_{3 R}^{e}\right)\left(1-\frac{20}{9} \sin ^{2} \theta_{w}+\frac{4}{3} T_{3 R}^{u}-\frac{2}{3} T_{3 R}^{d}\right)\right. \\
& \left.+\left(1-4 \sin ^{2} \theta_{y}-2 x_{n}^{e}\right)\left(1-\frac{4}{3} x_{3 B}^{u}+\frac{2}{3} x_{3 D}^{d}\right)\left(1-(1-y)^{2}\right) /\left(1+(1-y)^{2}\right)\right]
\end{aligned}
$$

Notice $A$ is $x$ independent. For any larget

$$
\begin{aligned}
& f_{u}(x)=M_{p} E_{u}^{P}(x)+k_{d} f_{d}^{P}(x) \\
& f_{d}(x)-k_{p} f_{d}^{P}(x)+k_{d} f_{u}^{P}(x)
\end{aligned}
$$

Thus we aee that if $x_{p}-t_{h}$ then $\varepsilon_{u}-f_{d}$ and hence $f(x)$ cancelo out in clve ratio A. I remark al6o that vith right-hended atgglet assignnent tor all quarks and leptons the prediction bucomes $y$-independent for ol ${ }^{2} \theta_{H}=.25$, or slowly varying wth 8 for $\sin ^{2} \theta_{y}$ near thot value: and the present best valuee ate quite elose to .25 . This is in marted contragt to some other models, for example, models with wontrivial $\mathbf{r}_{3 R^{\circ}}$ Models auch as $5 U(2)_{L} \times s U(2)_{R} \times U(1)$ (Ref, 18) have alao been constructed to reproduce the atandard WeInberg-Salam predictions for deep Inelsatic y-scattering, but can gave atice different predictione for perity volating effects, in particular for the atomic pbysice exparymente they predict no effect. The result of the suc-Yale experiment 19 
olong wth the predictiono of Welnberg-Salam and of a theary with the rLght-haded electron in a doublet is ohow in F19. 10. Ta1s rosult io lo in conflict wth the version of $s U(2)_{L} \times s_{(2)_{R}} \times v(1)$ which givee no atomic phygies partty violations. Furtior 1nformacion, in particular on the relative $u$ and d couplinge is goined frote dece on hydrogen. 19 The stac-Yale collaboracion intends to whe further measurements ior

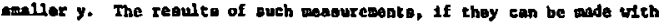
exrore comparable to those of the exiating moasurement, w11 provide very taterateing fucther information.

Cabn and Gilman have 1 so calculated predictions for asymatrieg for

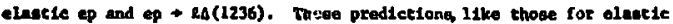
up cotal eross eections, depand on some asouptions about form factora, but one could obtaln wans furthor teste of the model by masuring these quatictes.

How we came to the "Kares Heac" far Helnberg-Salem, the qualtion of partity violactons in acomic physies. These axe of course tests of come of the wap parametors In the oodol as oceur In ep and ed scatcering at gmo. (One neede both ep and ed to be ablo to test up and dowp quark couplinge aeparately.) In the etoric phystes expertmente vint is measuxed is the optical rotation of 1 ght in a leger Induced atomic transit1on. This effect is proportional to the matrix element far the mixing of a "youg pactity" state dua to the axinl coupling of the $z$ to en electros. In welaberg-Salam $s_{A}^{*}--1 / 2$. At the nucleus we need a $B_{V}$ 
coupling, which is gtven by

$$
\begin{aligned}
& B_{u}\left(\frac{1}{2}-\frac{4}{3} \sin ^{2} \theta_{u}\right)+N_{d}\left(-\frac{1}{2}+\frac{2}{3} \sin ^{2} \theta_{u}\right) \\
& \text { - }\left(2 w_{p}+x_{s}\right)\left(\frac{1}{2}-\frac{4}{3} \operatorname{\theta in}^{2} \theta_{v}\right)+\left(2 x_{s}+w_{p}\right)\left(-\frac{1}{2}+\frac{2}{3} \operatorname{ain}^{2} \theta_{v}\right) \\
& --2\left(\sin ^{2} \theta_{W}+\frac{A-2 z_{i}}{2 z}\right)
\end{aligned}
$$

Bonever this is the easy part of the colculation, the baxd pert is the cootent of proportionality, which 1 s to say the calculation of the atomie phyoleg matrix elewents

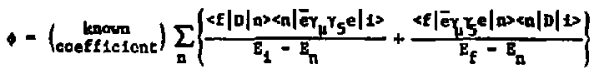

where $D$ is an olectric dipole operator. To colculate this one negds to know the energy leveln and the relevant wave functions for the atom in queation, which to Blowuth in all experfweats carfied out to this date.

The energy levele are woll wesaured, but the waye functions are not as easily obtatned. One makes wodelo for them, and the models axe tested by thair ability to reproduce certetn measured reaults, such as enerog levels. I diaplay in Table I as an example a table frot a paper by Henley, Knpliech and Whleca. ${ }^{20}$ ar in this table meane ". pafiguration interaction." The point of the paper ta that the original calculatione by Hanley and wilets of the expacted partty violaties effect used a Hartreo-Zock Independent-particle wodel, Including the conflgurat 100 Interaction corrections changes the predicted effect by as much as 0.65. Yau way judge for yourgelves frow the table the extant to whtch the energy levels cooftrm theso corrections.

There are independent calculationg by Lovkov, Bughkov, and Khriplavich ${ }^{21}$ which take what they call a aemi-empirteal approach. Thts leans 


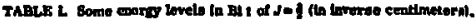

\begin{tabular}{|c|c|c|c|c|}
\hline terel & Whant CI & $\begin{array}{c}\text { Cl Delodin } \\
7 \%\end{array}$ & CI Inchiding & Expl." \\
\hline 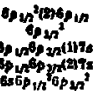 & $\begin{array}{l}\text { L1 ass } \\
34800 \\
12074 \\
18686 \\
01298\end{array}$ & $\begin{array}{l}11590 \\
31994 \\
4810 \\
48595\end{array}$ & $\begin{array}{l}11784 \\
23364 \\
94828\end{array}$ & $\begin{array}{l}11418 \\
3 j 164 \\
14865 \\
494 \%\end{array}$ \\
\hline
\end{tabular}

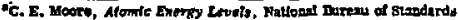

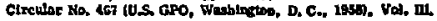


that adjugtments are made in the model to eorrect certain predictions to match measured values. Unfortunately some corrections have to be made besed on weseurewents in Thallium recher than Blamuth, aince the rolevant magurement is oot avallable for B1. The relevant quantity is

$$
0_{6}=\int d r r^{3} R_{68} R_{p_{3 / 2}}
$$

thete $R$ is the radial part of relevant vave function. For Thallium the model prediete

$$
P_{6}=-2.9 a_{0}
$$

and photolonization weasuremante $g^{\text {tve }}\left|\mathrm{o}_{\mathrm{o}}\right|=1.8 \mathrm{o}$. Henee the affect of a $6 s+6 p$ electron eranaition in Bdsmuth 18 corrected by a factor (1.8/2.9) frow the theoretical prediction. There are other relevant conertbutions coming from $6 \mathrm{p} \rightarrow 7 \mathrm{~s}$ and $6 \mathrm{p}+$ thigher atates including constound for which the estimates are made ofinilarly, but with reference to teate In BI. In celculating the total predicted effect the relative alpos of these vartous contributions are very imporcant. (The above discugelon was given, with opme further detafl, In a talk by Peter Rosen at the Workghop on Weak Interactions at Ames, Iowa last month,) 22

Where does all this lenve wo-aftar all correctlons have been applied the beet value for the predicted effect, for cither the 876 or $643 \mathrm{~nm}$ line $1 \mathrm{a}$ of order $-10 \times 10^{-8}$ using $\sin ^{2} \theta_{0}=-2-.25$. The experieatal situstion will be discused in detall at the Topical conference next week. There are now four expertmencs, tuo from Sentele, one from oxford and one from Hovostbirgk. of these, three Including the second generation Seattle expertmenc, glve an upper limit about on order of magattude below the prediecion while the fourtb, froto Novoaibirsk findo 
an effect in agreewent with the predicted value. Obvlously not ayaryone I. Eight--there are several optiong, among them

1. Movoabirak, Atomic Theory and Welabarg-Salam ara right and Oxford and Seative are wrong.

2. Hovolbirak and Atomlc Thoory are srong and NetnbergSalam, Oxford, and Seattla are right.

3. Howstbtrok ood Neinberg-Salmore arrong and Atonde Fhysies, Oxford, and Seatcle are right.

4. Everyone 1a voing.

I do not totend my provious discumation to be a judgment on the atomic phyoses theory. I have not studied it carefully erough to gake such a judgment, Clearly there are some uncertainties, but the quention is vhethar they are at the factor of 2 level or as wuch as an order of masnitude. Ope mut alo look very carefully at she experimanta to try to underatand wat wight posstbly be going wrong in any one of them, eince they disagree. These are difficalt neasrenente but I do not knou of ony telling point which hoo been raieed agatnet any one of chew, all I can wey is the digeuaston noxt Vednasday promista to be Interesting. The olcuation ay aleo be reoolved by furcher experimeato, An experiant to Thellitem in beiog worked on at Derkeley, which hes the virtwe that cartatn cross-checks of the model can be made at the agose time. Fro the theortote polat of view the ideal experiment is of courge in hydrogen. This wil cose; groups at Hichigan, Seatele, and Yale are working on 1t. Reaulte aze not expected for same time. (Pradistions vary frow a few wonthe to wore than a year.) 
For the wost part the copposite quark p1cture of hadrons, rogathur with a gauge theory of the reak interactions, giveo us a good dencription of the obaerved weal interactiods. Let me list some galient pointes We do nat see gecond cless surrents, ${ }^{23}$ (Thets extstence would te a aerlous problew, If not a dieagter for these theorteo.)

Deep Inelastie neutrino ocattering data 18 for the most part vell fit by the model: we do not aeed to 1moke ecelat cowponent, which would give a term propoteionol to ( $1-y)$ In $d \sigma / d x d y$, though such a contribution 1s also not excluded by the present date. One outatand Ing problem here 10 the ratio $\sigma_{\mathrm{L}} / a_{\mathrm{T}}$ wh1ch $1 \mathrm{~s}$ found in electron acattering whtoh, even tucluding higher order gluon effects, 18 predicted to be somerbet waller then the magured veluse. ${ }^{24}$ This quantity anot be dominated by terme tovololug mass corrections, terms dropped in all the stindard asymptotic (scaling) creatmante. Varlous attempts ${ }^{25}$ hove been wade to eetinnte weh effects, it ig a pretty grubby business. From a pragmatic point of vies 16 1s fast to keep the magnitude of $\sigma_{L} / \sigma_{T}$ in wind as a measure of the oxder of angaicude of poanthle corrections to the quack model plun GCO treatment whth we have discussed.

There are and areas where the theory ceases to be useful. It is a theory of the weak interactioss of quarks and not of phyelcsi hadrogs, In deep Inelostic acaterering we could abeorb our 1sporance of the hadros vare function into fow atructure fumetlops and then coupare expar1ments. For explatning hyperan dectys however we need to know tore. Certats aheolute rulas like $\Delta Q$ - $\Delta S$ arioe as a patural coagequenco of the structure of the quatk currents. However the $\Delta I$ in $1 / 2$ eahancemant, which 6cen Hojetkl discugsed on konday, to a decatled property of the hadrontc 
atr1x elewents of two quark currente. There are both $\Delta I=1 / 2$ and $\Delta I$ - 3/2 operatore formed fron these currents. Empirically we find the $\Delta I=1 / 2$ perto dowtnoted by a factor of 50-100. Keeplog higher ordar gluod correction, anomaloug dimenglong as diacuaged in the context of gcaling volations by John Ell1s, gives some At $=1 / 2$ anhancement, ${ }^{26}$ but 1t 10 ay judgment that with reasonable values of the parameters involved It Io not enough to fit the data, it 1e rore like a factor of 5 chan the factor experimentally observed. That does not men the chaory la urons, adply that the effect 18 dominated by the part whicb we cannot calculate. the long diatence part, rather than by the short diatance pare for wh1ch this celculation can be made. If wa really underatood hadrons as quark bound states we ohould be able to explain the effect, but that of courue 10 atrong Interaction problem, gauge theorieg of the veak Interactions can at present only make ueful predictions where such problene can be avoided. 27

There 1s another area of weak phenomenology which I have barely mentioned--the area of GP violetion. As Stan Wojeicki cold you on Mondey a stx quark version of Weinberg-Salam in general has some CP violating phase in the quark-mixing matrix which defines yeak eigenstates in terms of wass-eigenstates (or vice veraa). Adding more than one B1gBa doublot can also Introduce GP violating effects. John Ellis wll tell you tore about how these thinga vork. I Just vant to colment that these theories naturally 1ncorporate GP violating effects without having to add anything radically new. The simplest Heinberg-Salam theory with just four quark flavors and one complex HIgge doublet doeg not have CP-violacions, but experimental resulcs are already pushing us beyond that model anyway. 


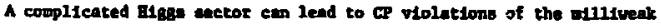
type, ulth a pradicted value for the neutron dipote woent oct weh beloy the present experinental upper boind. ${ }^{28}$ The co violntions coming fros phases to the quark aetor are typlcally ouperweak in cheracter. The GP violating phase in thie case, like everyching else coming frod the Yuksus coupling cerws, in a free paremeter in the wodel.

I howe trind in these loctures to give you wore feeling for the genorality of the gutuge theory 1den, as vell as of the atatus of the

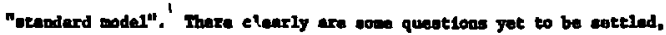
but in tbe lifot year auch progreal hro been rade. A year ago there wero

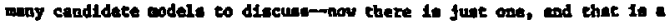
very economicel one. A viable nodel mut at last raprodues the anttrino phenomagology of the Vainbarg-Snlew tadal. There it a large elass of modale of the type $5 v(2) \times u(1) \times G$ which do $405^{29}$ the pertity violetion sftuation woy force ws to extend the aodel in this wey. There are

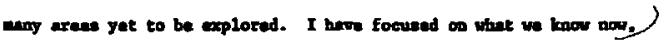
lewing John Bllis ath the problee of opeeding his next three lectures telling about thinge we know practieally nothing about, at least exper1workally apeaking. 


\section{Deforences}

1. B. Winberg, Phyo. Bev. Lattera 19, 1264 (1967): A. Salam in teicatary Partiele Theory, ed. by $n$. Svartholm (Almquiat and theoll, Btockhold, 1969), p. 367 .

2. 8. Glabhos, J. ILloupoulos and L. Malani, Phys. Rev, D 2, i285 (1970).

3. C. 'c llooft, Huel. Phye. B33, 173 (1971), 1935, 167 (1971): B, H. Lee and J. Zinit-Justin. Phys. Bov. D 5, 3121 (1972), 5, 3137 (1972), S. 3155 (1972) and I, 1049 (1973).

4. J. Cormall, D. Levin and G. Tiktopoulos, Phys. Rev. D 10,1145 (1974). also Phys. Rev, Letcers 30, 1268 (1973) and 31.572 (1973): C.E. Levellyn Solth, Phya. Letters 46B, 233 (1973).

5. J. Bjorken and C. H. Levellyn Smith, Phys. Rer. D I, 887 (1973).

6. 5. I. Glastow and S. Watnberg. Phyo, Rev, D 15, 1958 (1977);

B. A. Panchos, Phys. Rev. D 15,1966 (1977).

7. 8. Wainbarg, Phys. Rev. Laterera 29, 1698 (1972).

8. Thta difcusaton ts presented in the Lapusge of the unttary gauge, Tor ealculational conveatunce it to often betcer to vork in one of the endfeatly renoralizable gauges for an introduction to such perogen; see B. 8. Abers and B. U. Lee, Bhyates Reports 9C (1973).

9. y. Eolder et al. (GDas), Phys, Lettere 72B, 254 (1977); J. Blletbchen et e1. (Gecgatielie), Muel. Bhys. B118, 218 (1977); A. Benvenut1 et al. (바T), Phye. Rev, Leters 37, 1039 (1976); P. Wanderer et al. (dPrif). Phya. Rev. D 17, 1679 (1978); P. S. Merritt et al, (CF). Thye. Bev. D 17, 2199 (1978); $K$. Schulteze (BBBC), in Proc. 1972 Int. St-2, on Leptern and Phatoon Interactiong at High Bnarsies, edited by 7. Gutbrod (0EST, Banburs, 1977), p. 359; and P. C. Bosetti et al, Report no. Oxford-1pp-20/78 (1978).

10. Sal talks by Foreoon and Cormulns in these proceedinga and refarencos conteined thercin. For published epardmentel results see pature 264, 528 (1976).

11. J. 0. Bjorken, "Alternatives to Gauge Theories," talk given at the Ban Lee Keworial Conference, Fermilab, September 1977 (SLAC-PUE2133 and 2134). See also carlier vork by P. Hung and J. J. Sakurat, (1976).

12. J, D. Bjorken, Phys. Bav. 179, 1547 (1969).

13. G. Parta1, Phys. Letters 438, 207 (1973), 50B, 367 (1974); K. P. Polltzer, Physics Reports 14C, 4 (1974); G. Altarelli and G. Yar1s1. Vucl. Phys. B126, 198 (1974). 
14. This ptcture is taken from L. Abbotk and $M$. Barnett, "quarl and Lepton Couplinge in the Heak Interactions," Stanford Linear Accelarator Center preprint SLAC-PJi-2136 (see also Ref. 16). The date used are P. Allbran at al. (Garganelle P.S. $v_{y} e$ ), Phys. Letters

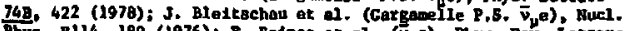
Phys. Bl14. 189 (1976); F. Relnes ex al. $\left(v_{\mathrm{e}} \mathrm{e}\right)$, Phys. Rev. Letrer: 37. 315 (1976): $H$. Baldo-Ceol.in (Aachen-Padua $v_{p} \mathrm{~B}$ and $\bar{v}_{\nu} \mathrm{e}$ ) to appear In Proceedinga of Heutrinos 78 Coptereace, Purdue, Aprll 28Hay 2, 1978. Recenc data ftom C. Baltay et el. on $v_{y}$ (Fermilab zaport) are in agreement wth the $90 \mathrm{x}$ conftdence 1 imils show. A recent reault frow tha Garganclla S.P.S. P. Altbran .. 1.., CERW/ EP/PHXS 78-6 (1978) doea not 4gree with chese regules jut the group have etated that analyele of further data changes the ragult. o this magurement ia not included here.

15. I. Sulak, Harvard raport to epposz in the Proceedings of the Neutrtnos 78 Conferonce, Purdun, April 28-lay 2, 1978, J. B. Straft and v. Kozaneck1, Harvard Univarglty Ph.D. Theges (1978); D. Cline et al., Phys, Bev. Lettara 31, 252, 648 (1976).

16. I. F. Abbot and R. H. Barrett, Phye. Rev, Latters 40, 1305 (1978) and SLAC-PUB-2136. See also talk by R. H. Earnetc in these proceedings.

17. R. K. Caks aod F. J. Gilasa, Phys, Rev, D 17, 1313 (1978).

18. J. Pat1 and A. Salam, Phys. Bov, D 10, 275 (1974). The pareicolar veroton to which I refer here ua distussed by A. Daikufula, B. Georg1 and s, L. Glashow, Ann. Phye, 109, 242, 258 (1977).

19. C. Pxegcott et al. "Parity von-Conservation in Inelaste Blectron Bcatter1ng," Stanford Linan Accelerator Center preprint BLAC-POB-. 2148 (July 1978). Sce aleo the talk by D. Shezden 2n these proceedinge.

20. E. Y. Henley, M. Xlapisch and L. MLlats, Phys, Rev. Leters 39. 994 (1977).

21. v. H. Novilkov, O. P. Suahkov and I. B, Mhriplowich, Th. Bekep. Teor. F1., 71, 1665 (1976) Sov. Phys. J.B.T.P. 44, 872 (1976) .

22. P, Rosen, Proceedinge of the Workghop on Weak Interecters, Iors State Univecaity, Anes, Ious (June 1978).

23. A. Braende, L. Grenacs, J. Lang, L. P. Roesch, V. L. Telegd1, P. Irut ctrann, A. Weler, A. Zohnder, and vuligen Sin, Phys. Rev. Lotters 느, 306 (1979).

24. A. De Rujula, H. Goozg1, and H. D. Politzer, Ann. Fhys. (N.T.) 103, 315 (1977). 


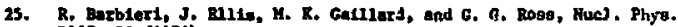
D117, 50 (1976).

26. K. T. Gasllerd and B. U. Le, Phys. Rev. Letrers 33, 208 (1974);

6. Altare2l1 and L. Kaiand, Phys. Letters 52B, 351 (1974),

27. For a "atace of the art" diecuseion of this gubject sae the telk by H. $K$. Callined in tbave procesdinge.

28. 8. Hatuberg, Phya. Bev. Letere 37, 657 (1976).

29. B. Gaorgl and S. Nelubers, Phys. Rev. D 17, 275 (1978). 


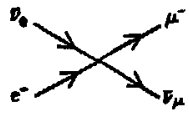

Fig. 1, Typical prosess in fnur-fermi theory.

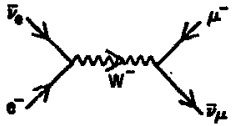

P18. 2. Jotroduction of an Intermediate vector bosen to modify the atuplitude ahoon in Fig. 1.

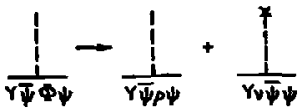

P1g. 3. DLagrematic zopresentation of the change of variables 1 - otv.

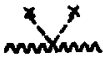
Jat4az

F18. 4. Bffective gluon mass term generated by vacum erpectation value $v$. 


$$
\ldots
$$




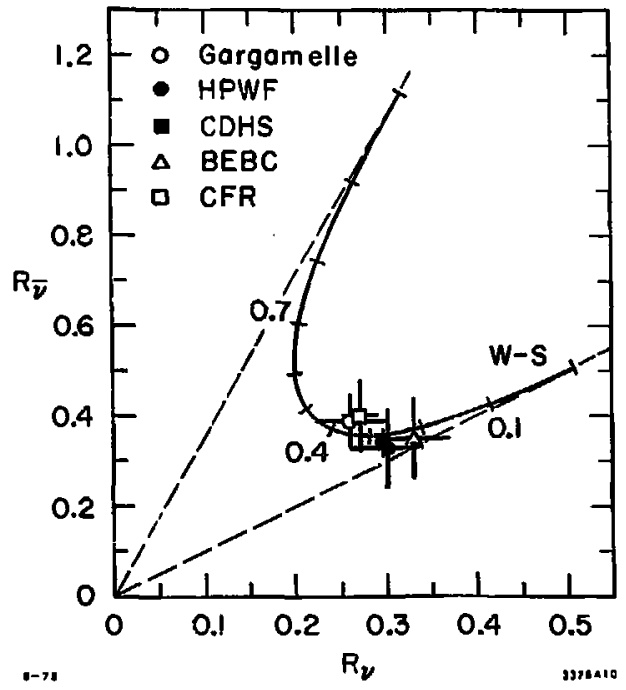

Fig. 6. The ratio of nautral-current to charged-current total crops sectione for peutrinos $\left(R_{Y}\right)$ and antiuavtrinos $\left(R_{-}\right)$ocatterine of equal numbers of neutrons and procons. The solld line is the atandard nodol prediction lor various $a^{2} \mathrm{n}^{2}$ values. The dashed linas epclose the area allowed by adding a triplet of rifges bosons. 


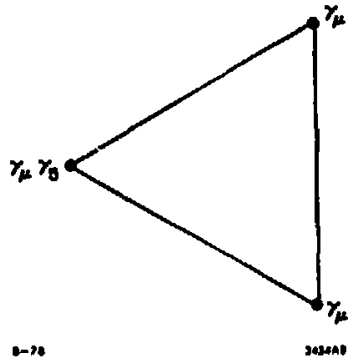

F18. 7. The enoralow trianglo graph. 


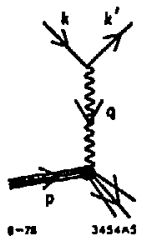

Fig. 8. Labeling of momenta In deep inelastic cattering processes. 


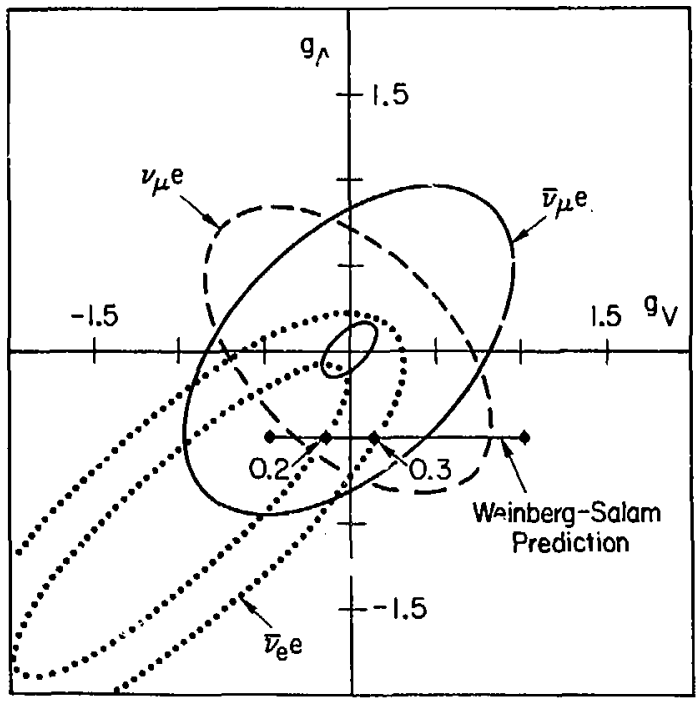

0 Fig. 9. Experimental congtraints on $\varepsilon_{V}$ and $g_{A}$ irow lepton
scactering dato. 19 


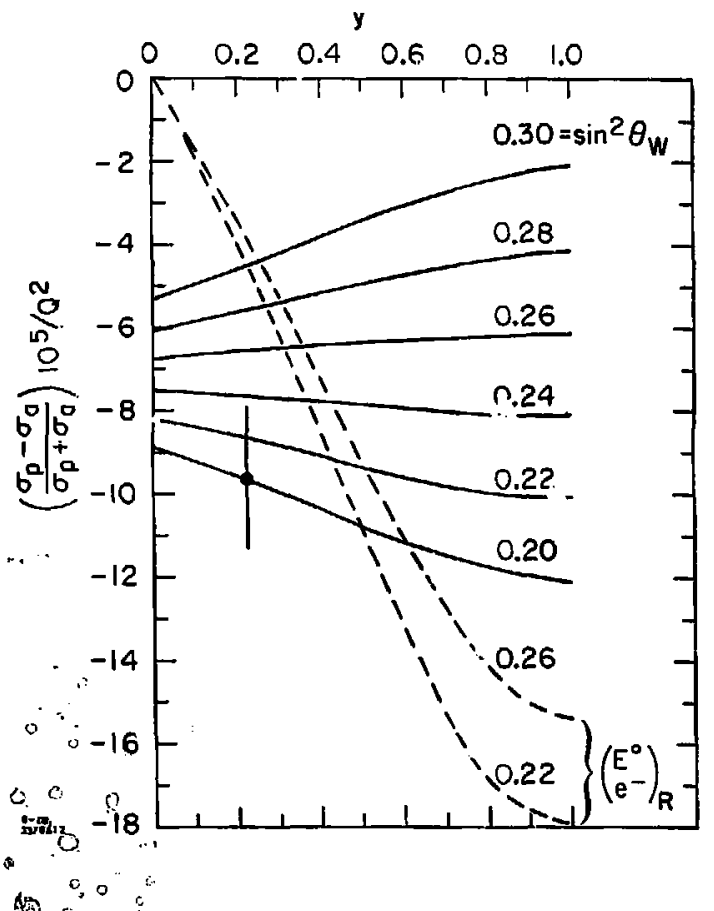

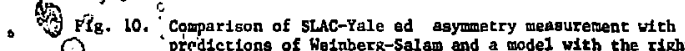
$c$ Q "preidictions of Wofuberg-Salaw and a model with the rightS. hauded electron in a doublet. 